\title{
O Perfil de Professor que Jngressa e que se Forma no Curso de Letras-Português na Universidade Federal do Espírito Santo
}

The Portuguese Teacher Profile that Starts and Graduates from Letras-Português Course at Universidade Federal do EsPíRITO SANTO

Maria Amélia DALVI*

Resumo: Este artigo retoma parte das discussões encetadas em "E o professor de língua portuguesa sai da faculdade e cai na escola: estará apto a conduzir atividades de leitura e produção textual?" (DALVI, 2009), originalmente apresentado durante o $17^{\circ}$ Congresso de Leitura, na Unicamp. Naquele trabalho discutiu-se o perfil do estudante finalista da licenciatura plena em Letras-Português na UFES. Neste artigo, cerca de dois anos depois, propõe-se uma apresentação sumária do trabalho de então e acrescentam-se dados coletados em questionários aplicados aos estudantes calouros do mesmo curso no semestre de 2011/1. Como conclusão, procura-se provocar alguns discursos cristalizados em torno do tema.

Palavras-chave: Formação de professores; Ensino de Língua Portuguesa; Ensino de Leitura e Literatura.

Abstract: This paper revisits some of the discussions begun in " $\mathrm{E} o$ professor de língua portuguesa sai da faculdade e cai na escola: estará apto a conduzir atividades de leitura e produção textual?" (Dalvi, 2009), originally presented during the $17^{\circ}$ Congresso de Leitura (17th Reading Congress), in the Campinas's University. That text debated the graduating

* Licenciada e mestre em Letras e doutora em Educação. Professora do Departamento de Linguagens, Cultura e Educação e do Programa de PósGraduação em Letras da UFES. Contato: mariaameliadalvi@gmail.com 
students profile in the Letras-Português (Portuguese language) course implemented by Espírito Santo's University. In this article, about two years later, we propose a basic presentatiomn of the work and add new data collectes from questionaries answered by freshman students from the same course of $2011 / 1$. In conclusion, we try to provoke some unstability of around the theme.

Key-words: Teacher formation; Portuguese Teaching; Reading and Literature Teaching.

\section{Introdução}

Este texto, em sua primeira e segunda partes, retoma o artigo "E o professor de língua portuguesa sai da faculdade e cai na escola: estará apto a conduzir atividade de leitura e produção textual?”, publicado nos Anais do $17^{\circ}$ Congresso de Leitura do Brasil, ocorrido em 2009, na Universidade Estadual de Campinas, em São Paulo. A partir dessa retomada, que inclui revisão teórica e terminológica do trabalho original, acrescentam-se dados produzidos a partir de questionários aplicados pela coordenação de curso aos estudantes calouros da licenciatura em Letras-Português, no semestre letivo de 2011/1, na Universidade Federal do Espírito Santo (UFES). Concluise, previsivelmente, pela necessidade de se repensarem as práticas no âmbito da formação de professores de língua e literatura no Estado do Espírito Santo.

Em analogia à pergunta de Drummond "Por que motivo as crianças, de modo geral, são poetas e, com o tempo, deixam de sêlo?", na crônica "A educação do ser poético", perguntamo-nos: por que motivo os calouros da licenciatura em Letras-Português são leitores e querem ser bons professores e, com o tempo, ao se tornarem finalistas, deixam de ler, desistem ou desiludem-se com a formação e com a profissão docente? Embora entendendo que a pesquisa quantitativa (ou seja, produzida a partir do tabelamento de respostas, como aqui fizemos) não seja a mais adequada para detectar as representações atinentes à formação docente no âmbito da Licenciatura em LetrasPortuguês, pensamos que os resultados produzidos (sempre parciais, incompletos e sujeitos a novos olhares) podem servir como ponto de 
partida para repensarmos questões candentes em nossa inserção cotidiana na realidade da formação docente inicial e continuada, por meio do ensino, da pesquisa e da extensão.

\section{A formação de professores: breve retrospecto histórico}

A "formação docente" ou "formação de professores" nunca esteve fora da ordem do dia, no Brasil. Mas, especialmente após a atual Lei de Diretrizes e Bases da Educação (Lei 9.394/96) (BRASIL, 1996), que elevou a formação dos professores das séries iniciais ao nível superior, o tema tem angariado ainda mais estudos e debates e tem engendrado uma fecunda literatura crítica. Porém, os estudos e debates surgidos na esteira da nova LDB ou como consequência das atividades dos centros de pesquisa brasileiros não são consoantes entre si - embora indiquem, em sua maioria, a necessidade de se repensarem os rumos da formação docente inicial em nível superior, não apenas daqueles que atuarão nas séries iniciais, mas também dos que atuarão nos anos subsequentes do ensino fundamental e do médio (GATTI, 2000; 2002).

Por exemplo, as Diretrizes Curriculares Nacionais para o Ensino Médio afirmam textualmente que o novo ensino proposto pela LDB vigente não se faz sem os processos de ruptura (com as práticas tradicionais) e transição (entre o já visto e o por ver), mas que o "calcanhar de Aquiles" é a formação de professores:

A preparação de professores, pela qual o Ensino Superior mantém articulação decisiva com a Educação Básica, foi insistente e reiteradamente apontada como a maior dificuldade para a implementação destas DCNEM, por todos os participantes, em todos os encontros mantidos durante a preparação deste parecer. Maior mesmo que os condicionantes financeiros. Uma unanimidade de tal ordem possui peso tão expressivo que dispensa maiores comentários ou análises. Um peso que deve ser transferido às instituições de Ensino Superior, para que o considerem quando, no exercício de sua autonomia, assumirem as responsabilidades com o País e com a Educação Básica que considerem procedentes. (BRASIL, 2000, p. 99 - grifos do original) 
A profissionalização docente, a indissociabilidade entre investigação-formação-prática, as heranças simbólicas no entorno da escola e do magistério, a construção da identidade profissional, as questões de gênero, as diretrizes curriculares das Licenciaturas e sua efetivação nas Instituições de Ensino Superior, os dilemas da Reforma Universitária, as narrativas e memórias docentes, os programas de avaliação de desempenho, as políticas públicas para a educação, as transformações nos processos de estágio, a inexorabilidade da formação continuada, os impactos da educação semipresencial ou a distância tudo isso vem compor o corpo de atravessamentos temáticos quando se pensa a formação de professores no Brasil (BARBOSA, 2006). De acordo com Helena Freitas (2002), sinteticamente poderíamos dizer que os debates sobre formação de professores evocam dois movimentos: o dos educadores e sua trajetória em prol da reformulação dos cursos de formação dos profissionais da educação; e o processo de definição das políticas públicas no campo da educação, em particular da formação de professores ${ }^{1}$.

Uma faceta mais específica dos debates relativos à formação docente (e que aqui nos interessa mais de perto) é consoante ao papel dos professores e professoras na apropriação da leitura e da escrita pelos estudantes brasileiros das escolas públicas - e, portanto, consoante à sua formação profissional para o desempenho desse papel. Assim, trazemos à baila o professor licenciado em Letras; não porque a preocupação com o exercício da leitura e da escrita seja exclusivamente tarefa do professor de português e respectivas literaturas ${ }^{2}$, mas porque

${ }^{1}$ A expressão mais visível de tais políticas está nos Referenciais Curriculares para Formação de Professores (1999), no Parecer 115/99, que criou os institutos superiores de educação, e nas Diretrizes Curriculares para a Formação Inicial de Professores para a Educação Básica em Nível Superior (2001).

${ }^{2}$ Carvalho defende que são necessárias mudanças na formação de todos os professores que atuarão na educação básica, visando a um domínio mais amplo da língua escrita, tanto em termos de produção, quanto em termos de recepção de textos complexos, uma vez que a questão dos usos da língua não compete apenas aos que vão ensinar português (CARVALHO, 2001). 
tais professores são parte inequívoca do processo ${ }^{3}$. Para Carvalho (2001), os licenciandos de hoje, com suas próprias dificuldades de leitura e de escrita, terão em breve a responsabilidade de fazer com que crianças e jovens usem a leitura e a escrita dentro e fora da escola para fins sociais de comunicação, expressão, busca e registro de informações e fruição da literatura como experiência estética.

Todavia, ao contrário do que se poderia pensar até aqui, este trabalho não se debruça propriamente sobre a formação do professor de português. Discute, antes, o fato de que a(s) representação(ões) deste professor (para si mesmo e para os outros) em relação ao exercício profissional (o que inclui uma avaliação de sua formação docente inicial) interfere $(\mathrm{m})$ diretamente nas práticas de ensino-aprendizagem das linguagens oral e escrita; afirma isso porque, para Berger e Luckmann (1994), há correspondência entre os significados do indivíduo e os significados dos outros, no mundo que partilham em comum; e também porque, de acordo com Chartier (1990), as representações articulam-se inelutavelmente às práticas.

O licenciado em Língua Portuguesa sai de seu curso de graduação habilitado ao exercício da docência em classes de $6^{\circ}$ ao $9^{\circ}$ ano do ensino fundamental e de $1^{\circ}, 2^{\circ}$ e $3^{\circ}$ anos do ensino médio. Todavia, temos percebido que muitos dos licenciados ou licenciandos em LetrasPortuguês demonstram uma imensa insegurança relativa à própria formação e, assim, à própria competência para o exercício profissional. Também Celso Ferrarezi Jr. (2008) chama a atenção para este dado, e o complementa dizendo que existe uma carência de formação que gera uma prática semimorta de ensino de língua materna, confirmada pela chatice atribuída pelos alunos às aulas e pela ausência de sentido no que se faz naquelas que deveriam ser as aulas mais interessantes da escola: as aulas de línguas. Isso ocorre, conforme o autor, porque há um consenso generalizado no país de que a formação de docentes nos estabelecimentos de ensino superior está longe de considerar o campo

${ }^{3}$ Sabine Vanhulle propõe mudanças na formação de professores de língua materna a partir da participação conjunta das faculdades de Letras e de Educação, uma vez que tais professores têm um papel preponderante na aquisição da leitura e da produção linguística oral e/ou escrita por parte dos estudantes da escolarização básica (VANHULLE, 2000). 
real de trabalho dos profissionais da educação. Talvez essa constatação possa ser explicada a partir de um retrospecto histórico.

A criação e o estabelecimento de cursos destinados precipuamente à preparação de professores para o exercício do magistério estão vinculados à institucionalização da instrução pública e, também, à secularização da educação (CATANI; OLIVEIRA, 2000; FIGUEIREDO; COWEN, 2005; SAVIANI et al., 2006; e TANURI, 2000). No Brasil, a criação das chamadas "escolas normais" resultou de uma importação de modelos europeus (o que explica, ao menos em parte, seu caráter "transplantado" e se justifica pelas contradições internas inerentes à nossa sociedade). Tal modelo coincidiu com o projeto do grupo social mais conservador, a classe senhorial, de consolidar sua postura política e ideológica e, assim, assegurar sua hegemonia (VILELLA, 1992). Como isso se fez? Basicamente, pela redução do currículo de formação do professor a um currículo mínimo, que compreendia, normalmente: a) apenas noções básicas de língua portuguesa, matemática, história, geografia e de "doutrina cristã"; e b) uma rudimentar formação pedagógica, de caráter essencialmente prescritivo.

De lá para cá, os cursos de formação de professores têm sobrevivido a diversas mudanças de rumos, até desembocar na atualidade, em que, por exemplo, a Associação Nacional para a Formação de Profissionais da Educação (Anfope) se vê na obrigação de sugerir ou solicitar ao poder público que as políticas de formação inicial privilegiem o caráter científico e acadêmico, ao invés do caráter técnico-profissional. Ora, este brevíssimo retrospecto nos faz deduzir que, se ainda é necessário explicar ou justificar, como o faz a Anfope, a importância de as políticas de formação inicial privilegiarem o caráter científico e acadêmico, ao invés do caráter técnico-profissional, está provado continuar em vigor, ainda hoje, uma política de formação docente que propõe a redução do currículo de formação do professor a um currículo mínimo, reduzido aos saberes indispensáveis à reprodução do conhecimento, e não à sua produção, em sentido mais amplo:

O professor se constituirá socialmente [a partir do Mercantilismo, e até hoje] como um sujeito que domina um certo saber, isto é, 
o produto do trabalho científico, a que tem acesso em sua formação, sem se tornar ele próprio produtor de conhecimentos. [...] Não convivendo com a pesquisa e com os pesquisadores e tampouco sendo responsável pela produção do que vai ensinar, o professor (e sua escola) está sempre um passo aquém da atualidade. No entanto, sua competência se medirá pelo seu acompanhamento e atualização. Neste sentido, o professor emerge como categoria sob o signo da desatualização. (GERALDI, 1991, p. 86)

Todavia, como nos lembra Freitas (2002), em decorrência do esforço dos educadores e de sua trajetória em prol da reformulação dos cursos de formação dos profissionais da educação, os professores licenciados nas últimas décadas têm, ao menos parcialmente, clareza de que a formação que recebem não é adequada ao que a profissão lhes exige. É o que atesta, por exemplo, Celso Ferrarezi Jr. (2008, p. 9): "Nos cursos de Letras - e isso é opinião corrente entre a maioria dos professores de língua materna no país - a formação na área [...] é muito simplória". Se tal ocorre é porque, embora de maneira fragmentada, os licenciandos em língua portuguesa ouvem falar, ao longo de sua formação, que linguagem e ideologia são intrinsecamente vinculadas; que a concepção que se tem de língua determina relações de poder mais ou menos democráticas; que é necessário aprofundamento teórico para que o professor possa compreender com mais clareza as dificuldades pelas quais seus alunos passam na apropriação de habilidades linguísticas e para que possa propor estratégias de superação eficazes para essas mesmas dificuldades; que o livro didático não é ou não deve ser o principal instrumento de trabalho do professor de português; que compete (também) ao professor a ampliação do universo cultural de seus alunos, especialmente aqueles oriundos das classes populares; que é necessário formar alunos efetivamente leitores, alunos efetivamente críticos, alunos efetivamente aptos ao trabalho com textos das mais diversas procedências, inclusive considerando os cânones literários; que o ensino de língua e o ensino de literatura não se excluem; que o ensino de gramática não pode se pautar por uma concepção elitista e autoritária; que não se deve desprezar a modalidade de língua que o aluno traz consigo, oriunda de 
suas redes sociais; que não se deve trabalhar a produção de texto descontextualizadamente; que o professor deve partir de situações concretas para a formulação de problemas que exijam dos alunos a proposição de possibilidades de respostas às demandas da realidade; que o professor deve ser um pesquisador, consciente dos métodos que aplica e pautado em teorias consistentemente embasadas, etc. - o que talvez nos permita entender, ao menos parcialmente, o porquê de muitos dos licenciados ou licenciandos em Letras terem uma enorme insegurança relativa à sua formação e, assim, à sua competência para o exercício profissional: sabem que o que fazem ou o que farão não é "o certo", mas, por outro lado, não sabem ou acham que não sabem fazer de outra forma.

Destarte, num contexto em que: a) o tema formação docente está em voga; b) os estudos e debates mais fecundos na área da educação apontam a necessidade de se repensarem os rumos da formação docente no país; c) a participação do professor de português como língua materna na apropriação da leitura e da escrita é inequívoca; e d) muitos dos licenciados ou licenciandos em Letras têm uma enorme insegurança relativa à própria formação e, assim, à própria competência para o exercício profissional; faz-se necessário saber quem são, como se vêem e como se avaliam os profissionais egressos dos cursos de licenciatura em língua portuguesa, justamente para que se possa conhecer melhor a realidade da formação docente inicial nesta área e planejar e propor mudanças de rumo, que, certamente, refletir-se-ão na qualidade da educação básica. Queremos pensar quais são as representações acerca do curso de Licenciatura em Letras-Português e da profissão docente com que os estudantes calouros chegam à universidade e dela se evadem.

Parece-nos que pouco adiantaria investir na formação de pesquisadores altamente gabaritados, se o profissional que efetivamente estiver dentro das salas de aula continuar sofrendo da "síndrome de vira-lata" de que atualmente sofre: não se sente em condições de assumir as rédeas de sua própria formação docente, analisando-a criticamente em seus aspectos socioculturais, políticos e econômicos; não se sente em posição de concordar, discordar, divergir ou dialogar com a produção teórica com que toma contato (ou, pelo menos, deveria tomar) em sua formação inicial como professor; não se sente à vontade 
para ousar, para testar, para experimentar uma nova maneira de exercer sua habilitação - o que, sem dúvida, explica o engessamento de que sofrem as aulas de língua portuguesa país afora e, assim, os maus resultados do Brasil nos testes nacionais e internacionais, por exemplo, de leitura e escrita (por mais que possamos discordar de sua formatação, de sua aplicação e das conclusões para que apontam).

\section{Quem são e o que pensam os licenciandos em Letras- Português?}

\subsection{Os finalistas}

Em um primeiro momento, caminhando na direção de começar a entender como seria possível uma formação efetivamente mais adequada ao exercício profissional do professor de português como língua materna, na visão deste mesmo professor, aplicamos, no semestre 2009/1, questionários a uma turma finalista do curso de licenciatura em Letras-Português, da Universidade Federal do Espírito Santo. O questionário contava com 74 questões objetivas e 3 questões discursivas. Selecionamos de todas as questões propostas aquelas que têm relação mais direta com o ensino-aprendizagem de leitura e escrita e com a percepção do licenciando finalista quanto à sua formação docente inicial. Apresentamos a seguir tais questões, seguidas das alternativas propostas e dos percentuais ${ }^{4}$ de recorrência das mesmas.

11. Na sua infância, você teve acesso regular a bens culturais impressos (livro, revista, jornal, etc.)?

( ) $\operatorname{sim} .-57 \%$

( ) não. $-43 \%$

12. Na sua infância, você teve acesso regular a bens culturais não impressos (cinema, dança, música, show, teatro etc.)?
( ) $\operatorname{sim} .-29 \%$
( ) não. $-71 \%$

${ }^{4}$ Os dados estatísticos foram arredondados por aproximação. 
13. Atualmente, você tem acesso regular a bens culturais impressos (livro, revista, jornal, etc.), além daqueles com os quais toma contato na faculdade?

$\begin{array}{ll}\text { ( ) } \operatorname{sim} .-86 \% & \text { ( ) não. }-14 \%\end{array}$

14. Atualmente, você tem acesso regular a bens culturais não impressos (cinema, dança, música, show, teatro etc.), além daqueles com os quais toma contato na faculdade?
( ) $\operatorname{sim} .-71 \%$
( ) não. $-29 \%$

Os percentuais obtidos revelam que houve, com a graduação, o incremento de acesso a bens culturais, impressos e não impressos. No entanto, é surpreendente que, embora na condição de estudantes finalistas de uma instituição pública de ensino superior, ainda 14\% afirmem não possuir contato regular com bens culturais impressos fora do espaço da faculdade e $29 \%$ afirmem não possuir contato regular com bens culturais não impressos fora do mesmo espaço. Isso revela que: a) para além dos textos da faculdade, parcela significativa não acessa o sistema escrito de modo sistemático ou, se o faz, isso se dá sem consciência - o que dá a ver a desimportância desse sistema nos contextos sociais de que esses profissionais participam; e b) para além dos bens culturais não impressos acessíveis por via do curso de graduação, quase 3 em cada 10 professores egressos de curso de licenciatura em Letras não frequentam salas de cinema e teatros, não locam filmes, não participam de espetáculos de dança, não assistem a shows e exibições artísticas de nenhuma ordem ou, se o fazem, isso se dá sem que se reconheça tais vivências como próprias do âmbito artístico-cultural.

Já as questões 17, 18, 20, 22, 2325 e 26 do questionário aplicado têm como interesse os hábitos de leitura dos licenciandos:

17. Qual é o seu principal meio de obter informações cotidianas?

( ) internet. $-57 \%$

( ) jornal.

( ) rádio.

( ) revista.

( ) televisão. $-43 \%$ 
18. Com que frequência média você acessa a internet?

( ) mensal.

( ) quinzenal. $-14 \%$

( ) semanal.

( ) duas ou três vezes por semana. $-14 \%$

( ) diária. $-72 \%$

( ) não acesso a internet regularmente.

20. Com que frequência média você lê pelo menos um jornal (impresso ou não)?

( ) mensal. - 29\%

( ) quinzenal.

( ) semanal. $-29 \%$

( ) duas ou três vezes por semana.

( ) diária. $-42 \%$

( ) não leio jornais regularmente.

22. Com que frequência média você lê pelo menos uma revista (impressa ou não)?

( ) semestral.

( ) bimestral ou trimestral.

( ) mensal. $-14 \%$

( ) quinzenal. $-29 \%$

( ) semanal. $-43 \%$

( ) não leio revistas regularmente. $-14 \%$

23. Você assina ou tem acesso regular a alguma revista, periódico ou caderno de pesquisa (impressos ou não) relacionado à sua área de formação (Letras/Educação)?

( ) $\operatorname{sim}$.

( ) não. $-100 \%$

25. Com que frequência média você lê integralmente um livro de qualquer área?

( ) anual.

( ) semestral. - $29 \%$

( ) bimestral ou trimestral. - 14\% 
( ) mensal. - 43\%

( ) quinzenal. $-14 \%$

( ) semanal.

26. Com que frequência média você lê integralmente um livro da sua área de formação (Letras/Educação)?

( ) anual. $-14 \%$

( ) semestral.

( ) bimestral ou trimestral. $-58 \%$

( ) mensal. - $14 \%$

( ) quinzenal.

( ) semanal.

( ) há mais de um ano. $-14 \%$

( ) nuncali.

Os principais meios de obter informações cotidianas, para os licenciandos, são a televisão e a internet, sendo que mais de $70 \%$ deles acessa a internet diariamente. Isso mostra que a cultura do dia-a-dia não passa pelo sistema escrito impresso e mostra, também, que o componente visual e oral têm predominância. Outro dado que chama a atenção é o fato de quase metade dos respondentes afirmar que lê pelo menos um jornal diariamente. Como nenhum deles apontou o jornal escrito como principal meio de obter informações cotidianas, podemos deduzir que o acesso aos jornais se dá preferencialmente pela internet - e isso sinaliza a democratização da informação, por meio virtual.

Outro dado significativo é que mais de $85 \%$ dos respondentes têm acesso regular (mensal, quinzenal ou semanal) a pelo menos uma revista. Todavia, nenhum dos licenciandos assina ou tem acesso regular a alguma revista, periódico ou caderno de pesquisa relacionado à sua área de formação (Letras/Educação). Considerando-se a democratização da informação viabilizada pela internet, esse dado revela tanto o desinteresse pela divulgação de resultados de pesquisa recentes e/ou em andamento (normalmente veiculados por revistas, periódicos e cadernos de pesquisa), quanto um provável desconhecimento dos títulos mais importantes disponíveis ao estudante e ao profissional da área, seja nas bibliotecas institucionais, seja por outros meios. Ainda é 
importante notar que, se a média de leitura de livros dos licenciandos é bastante superior à média nacional, contudo, quase 30\% lê apenas dois livros anualmente (sendo um por semestre); e que quase 30\% lê um livro de sua área (Letras/Educação) em intervalo igual ou superior a um ano.

As questões 42, 46, 47, 51, 52, 53, 62 e 63 estão mais diretamente relacionadas à percepção do licenciando quanto à qualidade de sua formação inicial:

42. Na faculdade, que tipo de aluno você foi?

( ) excelente.

( ) bom. $-43 \%$

( ) mediano / irregular. $-57 \%$

( ) ruim.

46. Em qual das seguintes áreas você avalia que sua formação, durante o curso de graduação em Letras, foi de melhor qualidade? (Pense na resposta independentemente de qual área você tem mais afinidade ou gosta mais.)

( ) formação pedagógica. - $14 \%$

( ) língua estrangeira. $-14 \%$

( ) língua portuguesa.

( ) linguística. $-14 \%$

( ) literaturas de língua portuguesa. - 28\%

( ) literaturas estrangeiras.

( ) metodologia da pesquisa. - 14\%

( ) teoria da literatura. $-14 \%$

( ) não sei. $-2 \%$

47. Em qual das seguintes áreas você avalia que sua formação, durante o curso de graduação em Letras, foi de pior qualidade? (Pense na resposta independentemente de qual área você tem menos afinidade ou gosta menos.)

( ) formação pedagógica. - 14\%

( ) língua estrangeira. $-14 \%$

( ) língua portuguesa. $-28 \%$

( ) linguística. 
( ) literaturas de língua portuguesa. - 14\%

( ) literaturas estrangeiras.

( ) metodologia da pesquisa. $-42 \%$

( ) teoria da literatura.

( ) não sei.

Obs.: alguns estudantes marcaram mais de uma opção, nesta questão.

51. Como você avalia a sua formação para o exercício da atividade docente na área de língua portuguesa e respectivas literaturas?

( ) excelente.

( ) boa. $-43 \%$

( ) mediana / irregular. $-57 \%$

( ) ruim.

62. Você se sente preparado para atuar como professor de língua portuguesa e respectivas literaturas?

( ) $\operatorname{sim} .-57 \%$

( ) não. $-43 \%$

63. Você acha que a articulação entre teoria e prática pedagógica nas diversas disciplinas do currículo do curso de Letras foi satisfatória?

( ) $\operatorname{sim} .-29 \%$

( ) não. $-71 \%$

Pela impossibilidade de desenvolvermos neste espaço uma análise mais alentada dos dados apresentados acima, vale destacar: a) que nenhum dos entrevistados se reconhece como um aluno excelente no curso de licenciatura; b) que nenhum dos entrevistados avalia que sua melhor formação durante o curso se deu na área de língua portuguesa; c) que quase $60 \%$ dos licenciandos avaliam a própria formação docente inicial como mediana ou irregular e que mais de $40 \%$ dos licenciandos não se sentem preparados para atuar como professor de língua portuguesa e respectivas literaturas na educação básica (o que dialoga com o dado destacado em "a"); e, por fim, d) que mais de $70 \%$ não 
veem como ao menos satisfatória a articulação entre teoria e prática pedagógica nas diversas disciplinas do currículo do curso de LetrasPortuguês.

Assim, podemos concluir, ao menos parcialmente, que a(s) representação(ões) do professor de língua portuguesa (para si mesmo e para os outros) em relação à competência para o exercício profissional interfere $(\mathrm{m})$ diretamente nos processos de ensino-aprendizagem das linguagens oral e escrita - pois a perpetuação da "síndrome de viralata", além de inviabilizar uma postura inovadora e auto-afirmativa do exercício profissional, engendra e alimenta a manutenção do status quo: daí porque, de acordo com o levantamento realizado, mais de 70\% dos licenciandos avaliam os professores que tiveram, tanto na escola como na faculdade, como medianos ou irregulares. Temos, é claro, clareza das limitações desse tipo de instrumento e de tratamento de dados, mas pretendemos tão-somente mapear um perfil do estudante finalista de Letras-Português, e parece-nos que os dados produzidos permitem atestar a validade da opção que fizemos.

\subsection{Os calouros}

Dando continuidade a este primeiro levantamento, no início do semestre letivo 2011/1 aplicamos um novo questionário, diferente do anterior, aos estudantes calouros do curso de Letras-Português da mesma Universidade. Contava com vinte e sete questões e foi respondido por 44 estudantes (sendo 8 homens e 36 mulheres), ao fim da semana de recepção aos calouros, promovida pela coordenação de curso. Apresentamos alguns dados a seguir.

10. O que fez com que optasse pelo curso de Letras-Português? [Questão discursiva.]

Influência de professor - 5\%

Interesse pela língua/literatura/leitura $-70 \%$

Vontade de ser professor - $23 \%$

Realização pessoal - 2\%

13. Você tem o hábito de ler revistas e jornais (impressos ou eletrônicos)? 
Não $-9 \%$

$\operatorname{Sim}-91 \%$

14. Você tem o hábito de ler livros (impressos ou eletrônicos)?

Não $-9 \%$

$\operatorname{Sim}-91 \%$

23. Qual a sua expectativa em relação ao curso de LetrasPortuguês? [Questão discursiva.]

Conviver com diversidade cultural / aprender sobre cultura brasileira $-10 \%$

Realizar-me pessoalmente - 10\%

Adquirir conhecimentos sobre a língua/literatura - 27\%

Obter um diploma reconhecido - 5\%

Ingressar no mercado de trabalho / obter sólida formação profissional $-32 \%$

Preparação para a pós-graduação - 6\%

Terminar o curso com a certeza de que sou uma boa falante da língua $-2 \%$

Conhecer novas pessoas $-2 \%$

Resposta em branco ou incompreensível - 6\%

25. Você se imagina como professor de língua portuguesa e respectivas literaturas na educação básica (ensino fundamental e médio)? [Questão discursiva.]

Não $-6 \%$

$\operatorname{Sim}-78 \%$

Ainda não sei / tenho dúvida / por pouco tempo - 12\%

Só quero atuar no ensino superior $-2 \%$

Em branco - 2\%

Antes de abordarmos especificamente a formação docente inicial, é interessante percebermos que, entre os calouros, mais de $90 \%$ se declaram como leitores habituais, em contraposição aos concluintes que majoritariamente não se reconhecem como leitores habituais sequer na área de formação específica. Esse dado talvez pudesse ser explicado como uma distorção motivada pelo mascaramento da realidade, por 
parte dos calouros: como, talvez, quisessem causar na coordenação de curso uma impressão favorável de si mesmos, afirmam-se leitores assíduos. Ou, então, como uma percepção mais crítica por parte dos finalistas a respeito do descompasso entre o volume de leituras que imaginam satisfatório e o efetivamente realizado.

Vale a pena ressaltar, também, que a imensa maioria dos estudantes calouros (70\%) optou pelo curso de Letras-Português tendo em vista a afinidade com a área específica e que mais de $20 \%$ optou tendo em vista o desejo de ser professor de Português. Vemos também, pelas respostas dadas à questão 25 , que quase $80 \%$ se imaginam como professor da educação básica, sendo que outros $12 \%$ ainda estão em dúvida (ou seja, a rejeição ao exercício da profissão nas salas de ensino fundamental e médio é de apenas $8 \%$ ). No âmbito das expectativas quanto ao curso, a maioria espera por sólida formação profissional e por uma formação consistente na área específica, o que confirma os dados obtidos com as questões 10 e 25 e confirma, também, as explicações dadas, pelos discentes, para o desejo de atuarem nas salas de aula de educação básica: "é meu objetivo", "acho interessante o poder que um professor tem de transformar, mostrar a direção para seus alunos", "acho linda essa profissão e adoro ensinar", "ensinar é a atividade que mais aprecio", "o ensino de língua portuguesa pode transformar o sujeito", "quero fazer o melhor", "já imagino a minha turma e desejo aprender para ensinar a comunidade", "meu objetivo é levar cultura para a minha região" - a despeito da ingenuidade de certas concepções.

Essa visão "positiva” do curso e da docência na educação básica nos constrange quando retomamos os dados obtidos com os questionários aplicados aos estudantes finalistas, nos quais manifestam sua insegurança quanto à qualidade e à pertinência de sua formação profissional. Se nossos alunos são leitores, se escolheram o curso de licenciatura em Letras-Português por interesse pela área e não por falta de opção, se querem ser os melhores professores que puderem, então, do mesmo modo que nos ressoa a angústia do cronista ("Se as crianças são poetas, por que, com o tempo, deixam de sê-lo?”), vive em nós a certeza de que é sempre preciso perguntar: por que os potenciais bons professores de Português na educação básica, ao fim da formação docente inicial, não se confirmam? 


\section{Considerações finais}

Realizando, informalmente, com alguns membros do colegiado ${ }^{5}$ do curso de Letras-Português uma discussão a respeito dos dados aqui apresentados, ensaiamos possibilidades de resposta à nossa indagação: quem são nossos alunos e o que pensam sobre sua formação docente inicial? E formulamos uma questão derivada: por que os potenciais bons professores de Língua Portuguesa na educação básica não se confirmam, ao fim da graduação?

A primeira "conclusão" é que um questionário como esse, com as limitações de antemão conhecidas, não é bastante para nos dizer quem são nossos licenciandos: pelos senões do próprio instrumento, pelo nosso amadorismo (estatístico) na formulação das questões e no tratamento das informações, e porque muitas das coisas que nos interessariam como "dados" não são previsíveis e nem generalizáveis. É mister, pois, que possamos aprofundar nossas representações a respeito de quem são nossos estudantes na lida cotidiana nos espaços e tempos das aulas, dos estágios curriculares, das atividades de iniciação científica, dos laboratórios de práticas, dos eventos acadêmico-científicos - além de cotejarmos os dados já obtidos com outros complementares, como os questionários socioeconômicos disponíveis na Pró-Reitoria de Graduação e com os resultados dos processos seletivos para ingresso.

O risco que corremos ao nos debruçarmos de modo demasiado confiante nos dados aqui expostos e brevemente analisados (sobre o perfil dos finalistas e calouros, e sobre sua visão a respeito da formação docente) é o de nos apegarmos a eles, sem levarmos em conta que de um semestre a outro, de um ano a outro, o corpo de graduandos oscila, varia. Algumas das respostas dadas por uma turma poderiam ser bastante diferentes das dadas por outra, anterior ou subsequente embora creiamos numa estabilidade dos dados fulcrais. Afora isso, a confiabilidade dos resultados está, é óbvio, afetada pela representação que os estudantes fazem dos aplicadores do questionário, da situação social (de finalização ou ingresso no curso) em que estão inseridos, etc.

5 À época da produção e análise dos dados, a autora fazia parte dessa equipe. 
A segunda "conclusão" é que não temos, também, como saber se nossos egressos se tornarão, ou não, "bons" professores - inclusive (para além da impossibilidade de lhes acompanharmos as práticas cotidianas) porque não há um consenso entre os formadores (e talvez nem precise haver) sobre qual é o professor de Língua Portuguesa que queremos. Pode ser que, se nos dedicássemos a saber que professores queremos, pudéssemos traçar estratégias comuns e aproximar ações: nisto há uma demanda de pesquisa. Porém, o que nos parece irrefutável é que, ao longo da formação docente inicial, nossos estudantes "aprendem" que sua formação é ruim, é insuficiente, é desarticulada do campo de trabalho, etc., o que, descontado o descompasso entre a idealização dos ingressantes e a experiência efetivamente vivida pelos concluintes, contribui para a avaliação negativa dos finalistas.

No entanto, o que parece urgente é pensar os discursos das comunidades de interpretação envolvidas, cristalizados em torno da formação docente inicial - porque, se acreditamos que as práticas e as representações estão inelutavelmente entrelaçadas (CHARTIER, 1990), conhecer quem é e o que pensa o professor de Língua Portuguesa em formação nos permite intervir nos processos levados a turno institucionalmente.

\section{Referências bibliográficas}

ANFOPE. As diretrizes curriculares para a graduação e os cursos de formação dos profissionais da educação. Disponível em: <http:// www.lite.fae.unicamp.br/anfope/>. Acesso em: 19 jul. de 2008.

ANFOPE. Boletim da Anfope, a. 13, n. 1, out. 2007. Disponível em <http://lite.fae.unicamp.br/anfope/novo/html/ boletim_outubro_007.html>. Acesso em: 20 jul. 2008.

BARBOSA, R. L. L. (Org.). Formação de educadores. São Paulo: Unesp, 2006.

BERGER, P. L.; LUCKMANN, T. A construção social da realidade. 11. ed. Petrópolis, RJ: Vozes, 1994. 
BRASIL. Ministério da Educação e do Desporto. Lei no 9.394, de 20 de dezembro de 1996. Estabelece as diretrizes e bases da educação nacional. Diário Oficial da União, Brasília, DF, 23 dez. 1996. p. 27833. Disponível em: <http://www.planalto.gov.br/ccivil_03/leis/ L9394.htm>.

Secretaria de Educação Básica. Parâmetros Curriculares

Nacionais: Ensino Médio. Brasília: 2000. Disponível em <http:// portal.mec.gov.br/seb/arquivos/pdf/blegais.pdf>. Acesso em: 20 dez. 2010 .

CARVALHO, M. A leitura dos futuros professores: por uma pedagogia da leitura no ensino superior. Teias, Rio de Janeiro, n. 5, p. 7-20, 2001 (jun. 2002).

CATANI, A. M.; OLIVEIRA, R. P. de (Orgs.). Reformas educacionais em Portugal e no Brasil. Belo Horizonte: Autêntica, 2000.

CHARTIER, R. A história cultural: entre práticas e representações. Rio de Janeiro: Bertrand Brasil, 1990.

DALVI, M. A. E o professor de Língua Portuguesa sai da faculdade e cai na escola: estará apto a conduzir atividades de leitura e produção textual? In: CONGRESSO DE LEITURA DO BRASIL, 17. Campinas, 2009. Anais... Campinas: ALB, 2009.

FERRAREZI Jr., C. Semântica para a educação básica. São Paulo: Parábola, 2008.

FIGUEIREDO, M. C. M.; COWEN, R. Modelos de cursos de formação de professores e mudanças em políticas. In: BROCK, C.; SCHWARTZMAN, S. (Orgs.). Os desafios da educação no Brasil. Rio de Janeiro: Nova Fronteira, 2005. p. 181-196.

FREITAS, H. C. L. de. Formação de professores no Brasil: 10 anos de embate entre projetos de formação. In: Educação \& Sociedade, Campinas, v. 23, n. 80, p. 136-167, set. 2002. 
GATTI, B. A. Formação de professores e carreira. 2. ed. Campinas: Autores Associados, 2000.

- A construção da pesquisa em educação no Brasil. São Paulo: Plano, 2002.

GERALDI, J. W. Portos de passagem. São Paulo: Martins Fontes, 1991.

SAVIANI, D. et al. O legado educacional do século XX no Brasil. 2. ed. Campinas: Autores Associados, 2006.

TANURI, L. M. História da formação de professores. Revista Brasileira de Educação, São Paulo, n. 14, p. 61-88, mai.-ago. 2000.

VANHULLE, S. La littérature dans la formation des futurs enseignants. Les cabiers du Service de Pédagogie Experimentale. Service de Pédagogie Experimentale. Université de Liège, n. 1 et 2, Jan. 2000.

VILLELA, H. de O. S. A primeira Escola Normal do Brasil. In: NUNES, C. (Org.). O passado sempre presente. São Paulo: Cortez, 1992. p. 17-42. 